\title{
М. Накагами
}

\section{Появление и развитие женских журналов в России и Японии (вторая половина XVIII-XIX в.)}

Реферат. Статья посвящена истории развития женских журналов, тесно связанной с изменением положения женщины в обществе. В России XVIII в. благодаря реформам Петра I и Екатерины II стало развиваться образование, повысился уровень грамотности. В результате этого женщины высшего сословия стали приобщаться к чтению как интеллектуальной деятельности. В 1779 г. Н.И. Новиков издал первый журнал для женщин, что положило начало появлению книг и журналов, ориентированных на эту группу населения.

В Японии первый женский журнал был издан для просвещения женщин в 1884 г. в период Мэйдзи (1868-1912), когда из феодальной страны она превратилась в монархию, были введены новые системы управления, в том числе в области образования. Появление женских журналов в Японии связано также с увеличением числа читателей-женщин и развитием системы женского образования в рамках государственной политики.

Отмечается, что форма внедрения концепции «женщина - добрая жена и умная мать» в России XVIII в. и в Японии XIX в. была разной, но данная концепция была принята в качестве основной идеологии женского образования. Цель настоящей статьи - проанализировать издание женского журнала и роль концепции «женщина - добрая жена и умная мать» в российском и японском обществе. Делается вывод, что женские журналы с государственной точки зрения, основывавшейся на данной концепции, в определенной мере выполняли функцию пособия по воспитанию идеальных женщин.

Ключевые слова: женский журнал, грамотность, чтение, читатели-женщины, женское образование, государственная концепция «женщина - добрая жена и умная мать» .

Для цитирования: Накагали $M$. Появление и развитие женских журналов в России и Яонии (вторая половина XVIII - XIX в.) // Библиотековедение. 2016. Т. 65, № 3. С. 323-328.

\section{Грамотность и женское образование во второй половине XVIII в. в России и в период Мэйдзи (1868-1912) в Японии}

В период XVIII - начала XIX в. общество сильно менялось. Ю. Лотман писал, что «женщина этой поры не только была включена, подобно мужчине, в поток бурно изменяющейся жизни, но начинала играть в ней все большую и большую роль. И женщина очень менялась» [1]. $\mathrm{C}$ помощью чтения и занятий интеллектуальной деятельностью российские женщины стали играть бо́льшую роль в обществе, хотя эта роль и была очень ограничена.

Приведем интересные сведения о грамотности. Согласно данным Б.Н. Миронова, в России в 1800 г. грамотность мужского населения в возрасте 9-15 лет составляла 4-8\%, женского $2-6 \%$, а в 1850 г. $-19 \%$ и $10 \%$ соответственно [2]. Например, в Англии, где уже образовалось гражданское общество, грамотных мужчин в 1800 г. было $68 \%$, женщин - 43\%. Это свидетельствует о том, что Россия в XVIII в. являлась

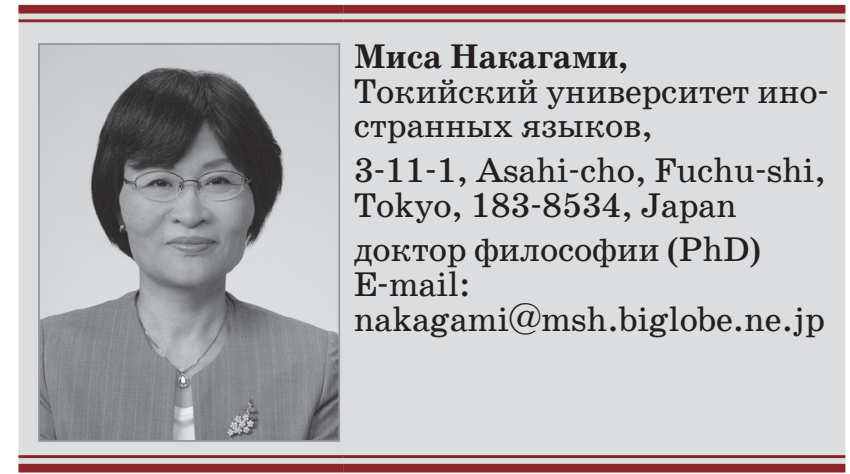

еще отсталым государством, и число женщин, имеющих возможность читать книги, было незначительным.

Проанализируем такую группу женщин, как читательницы-подписчики во второй половине XVIII в., на основе сведений, приведенных в монографии А.Ю. Самарина [3]: 82\% женщинподписчиков являлись представителями дворянства, более 86,5\% подписчиц жили в Москве и Санкт-Петербурге, а также в 46 провинциальных городах, что означает широкое распространение 
женского чтения. Круг интереса женщин-подписчиков составляли книги для детей, литература о домашнем хозяйстве и кулинарии. Таким образом, в России в XVIII в. читательницами были грамотные дворянки, имеющие денежные средства и интерес к чтению.

В Японии в 1850 г. грамотных мужчин было $54-75 \%$, женщин - 19-21\% [2]. Японский историк Ё. Амино пишет, что в эпоху Эдо (16031868) была создана государственная система по распространению грамотности среди населения [4] $]^{1}$. В конце периода Эдо в стране уже сформировался довольно широкий слой грамотного населения. Согласно опросу, проведенному в начале эры Мэйдзи (1868-1912) Министерством просвещения, предполагаемая грамотность у мужчин (судя по умению ставить свою подпись) составляла $50-60 \%$, у женщин - около $30 \%$ [5]. Причинами такой относительно высокой грамотности могут быть следующие факторы:

- в стабильном обществе без военных действий сформировалась культура городских жителей, которые чувствовали необходимость в освоении грамоты;

- активно развивалось издательское дело, рассчитанное на широкие слои грамотного населения;

- среди горожан пользовались популярностью развлекательные «прокатные» книги, такие как «Канадзоси» ${ }^{2}$, предназначенные для широкой читательской аудитории;

- в XVII-XIX вв. по всей стране распространилась система общественных или частных начальных школ «Тэракоя», где дети зажиточных горожан и крестьян обучались чтению, письму и счету.

K середине XIX в. в Японии действовало около 15560 начальных школ типа «Тэракоя». Таким образом, относительно высокая грамотность женщин стала благоприятным условием для формирования группы женщин-читательниц и появления женских журналов.

Вопрос о женском образовании в России впервые был поднят на законодательном уровне при Петре I. Позже, в 1763 г., И.И. Бецкой представил Екатерине II доклад «Генеральное учреждение о воспитании обоего пола юношества» о реорганизации в России дела воспитания детей. Целью И.И. Бецкого было создание полезной государству «породы людей», которые затем через семью должны были распространять принципы нового воспитания на все общество [6]. По его инициативе и в соответствии с указом Екатерины II «О воспитание благородных девиц в Санкт-Петербурге при Воскресенском монастыре» в 1764 г. был основан Смольный институт, первоначально называвшийся «Императорское воспитательное общество благородных девиц». Это общество, как говорилось в указе, было создано для того, чтобы «дать государству образованных женщин, хороших матерей, полезных членов се- мьи и общества» [7]. К началу XIX в. число светских учебных заведений было близко к 500 (в том числе 288 народных училищ), в них обучались 45-48 тыс. школьников [8]. В 1869 г. было решено открыть различного рода курсы для женщин.

В Японии в 1872 г. Министерством образования был издан указ о введении системы образования европейского типа, состоявшей из начальной и средней школ, университета, в которых могли обучаться все граждане независимо от социального сословия. Ставилась цель распространения системы начального школьного образования и подготовки кадров, для того чтобы как можно быстрее догнать по техническому и культурному развитию западные страны [9, с. 17-20]. Благодаря внедрению этой системы впервые японские женщины официально могли получать школьное образование. C 1886 г. была введена система четырехлетнего всеобщего обязательного школьного образования, посещаемость начальной школы мальчиками составляла 61,9\%, девочками - 29,01\% . В 1897 г. впервые доля женского населения, посещавшего школу, превысила 50\% . В 1912 г. этот показатель составлял 97\%, а число женщин со средним образованием превысило 90 тысяч. Предметами, которые изучали девочки в средней школе, являлись: английский язык, математика, естествознание, моральный кодекс, японский язык, шитье и домашнее хозяйство [10].

В соответствии с указом о школьном образовании было определено разделение по половому признаку, содержание предметов также было разным у мальчиков и девочек. В 1898 г. вступил в действие крайне «патриархальный» гражданский кодекс, в 1899 г. был издан указ о женском высшем образовании и четко определен курс женского среднего образования - подготовка добрых жен и преданных детям матерей.

Следует отметить, что в России процесс развития женского образования расширялся постепенно, около 100 лет. В Японии же подобный процесс осуществился за короткий период - менее чем за 30 лет, с 1872 по 1899 год. Японское общество очень быстро менялось, для того чтобы адаптироваться к европейской модели. В конечном счете, женщины начали обретать внутреннюю самоидентификацию, которая противостояла официальной идее правительства Мэйдзи - «назначение женщины - стать доброй женой, умной матерью и хорошей хозяйкой». Согласно этой концепции, в женском среднем образовании основное внимание уделялось, скорее, не умственному развитию, а воспитанию дисциплины и ведению домашнего хозяйства. Главное заключается в том, что в период Мэйдзи японские женщины получили право на образование, и в связи с этим резко увеличилось число женщин-читательниц. Курс женского образования был ориентирован на девушек из среднего слоя японского общества [9, с. 35-37]. Правительство Японии уделяло боль- 
шое внимание развитию среднего класса, потому что считало его ядром для обогащения и развития государства.

Целью воспитания детей в России при Екатерине II являлось создание «новой породы людей», при этом самую важную роль в семье должны были играть жены и матери, которые будут растить и воспитывать «новых людей». Можно сказать, что благодаря Екатерине II в российском обществе появились образованные женщины, примером которых считаются Е.Р. Дашкова и сама Екатерина II, основавшая в России систему женского образования. Ее развитие продолжила императрица Мария Федоровна, жена Павла I.

Таким образом, установление системы женского образования в России и Японии существенно отличалось, однако и правительство Японии, и Екатерина II и другие императрицы осознавали важность роли женщины в развитии государства и приложили большие усилия для развития женского образования, способствующего распространению официальной идеи подготовки «доброй жены и умной матери». Эта идея, сформулированная православной идеологией, уходит корнями в нравоучительную литературу XII-XVII вв.; она просуществовала очень долго, вплоть до начала XX века [11, 12].

В Японии существуют различные мнения по поводу возникновения идеи «добрая жена и умная мать». Многие ученые связывают ее с конфуцианством, патриархальным и феодальным укладами. В феодальный период Эдо издавались нравоучительные учебники, предназначенные женщинам, родившимся в семьях самураев и богатых горожан, с целью привить им необходимые добродетели. Однако в последнее время некоторые исследователи рассматривают данную идею как аргумент в пользу необходимости женского образования с государственной точки зрения в период Мэйдзи. Концепция «добрая жена и умная мать» до сих пор остается актуальной темой изучения.

\section{Появление и развитие женских журналов в России и Японии}

В 1779 г. в России появился первый женский журнал - «Модное ежемесячное издание, или Библиотека для дамского туалета» [13]. Как и в Европе, главным редактором и издателем ежемесячника стал мужчина - Н.И. Новиков. Если европейские журналы с яркими картинками были в основном посвящены моде, то русский издатель поставил перед собой цель «доставить прекрасному полу в свободные часы приятное чтение».

Женские журналы были предназначены для российских аристократок и отличались скорее литературной, нежели модной составляющей. В то время русские женщины читали в основном сентиментальные романы иностранных авторов. Многие мужчины считали это чтение вредным: в XVIII в. полагали, что если женщина читает книги, то она постепенно отходит от истинного своего предназначения жены и матери. В обществе преобладало мнение о том, что женщинам лучше воспитывать детей, а не читать. Комедия Д.И. Фонвизина «Недоросль», в частности, с точки зрения отношения к Софье демонстрирует консервативное отношение к женщине и ее роли в обществе.

Однако появление женских журналов свидетельствует о том, что в то время женщина-читательница уже существует в России и признается как группа читателей в обществе. Позднее стали издаваться разные специализированные женские журналы. Исключительной популярностью пользовался «Дамский журнал», который издавался князем П.И. Шаликовым. Жћурнал выходил два раза в неделю с 1823 г. до 1829 г. и далее еженедельно до 1833 года. Шаликов заявлял, что цель журнала - заменить читательницам дорогостоящую выписку из-за границы европейских женских изданий. Каждый номер открывался переводами романов или повестей французских авторов, в том числе Жॅанлис, далее следовали стихи, эссе, басни, в завершение непременно описания «парижской моды». С изданием сотрудничали П.А. Вяземский, А.И. Писарев, В.Л. Пушкин и др. Популярность этого журнала была столь велика, что многие признали его первым российским настоящим женским журналом. Однако в то время многие полагали, что приобретая знания, женщины теряют прелести своего пола.

В 1820-1830-х гг. в России издавались женские альбомы, сборники произведений, кроме того, в двух столицах развивались литературные салоны: А.И. Голицыной, 3.А. Волконской, Е.П. Ростопчиной и др. Наступил период подъема женской дворянской культуры. В обществе стали признаваться и расти роль и положение женщин, они стали более активно проявлять себя.

Жћурналы «Лучи» и «Звездочка», издававшиеся в 1840-1860-х гг. писательницей А.О. Ишимовой, были предназначены для воспитания будущих матерей и хозяек дома. Как пишет Л.В. Сокольская, «журналы для девочек А. Ишимовой символически связали периоды “рождения” и дальнейшего “взросления” русской женской журналистики, свидетельствуя в середине столетия о росте признания значения журналов для женщин в деле их просвещения и образования» [14].

В период Мэйдзи (1868-1912) правительство Японии усиленно стремилось к модернизации и европеизации государства согласно политике «обогащения страны и укрепления армии» и «цивилизованности и просвещения». Публикация первого журнала в Японии относится к 1867 году. Он назывался «Сэйё дзаси» (Западный журнал) и больше походил на газету, в которой размещается разная информация. Газеты сообщали о политических и социальных новостях, а журнал - о культурных новостях. После выхода первого журнала 
постепенно активизировалось издание жанровых журналов, в том числе женских, что свидетельствует о достаточном числе читательниц.

Первый женский журнал под названием «Дзёсэй синси» (Женский новый журнал) начали выпускать двое мужчин - К. Кондо и Ё. Ивамото в 1884 году. В первом номере они заявили о цели его издания - просвещении женщин, чтобы дать им возможность занять более высокую позицию в обществе. Однако журнал быстро прекратил свое существование, а в 1885 г. стал выходить универсальный женский журнал «Дзёгаку дзаси» (Журнал науки о женщинах). Его задачами являлись просвещение женщин, создание образца на основе соблюдения прав женщин в соответствии с западной моделью и сохранение идеалов женской добродетели, характерных для Японии. Главный редактор журнала Ё. Ивамото старался прививать христианский дух и уважение к идее европеизации. Он являлся учеником педагога М. Накамура, который в качестве руководителя группы японских студентов посетил Англию и вернулся в 1868 году. Увидев, что в Англии даже школьники обладают невероятными для японцев научными знаниями, которые получают от матерей, он осознал, что для развития государства, прежде всего, необходимо создать систему женского образования западного типа. В Японии в то время считалось, что женское образование должно включать в себя только знания и навыки, связанные с домашним хозяйством [15].

Журнал «Дзёгаку дзаси» пользовался популярностью не только среди женщин, но и у мужчин, издавался он довольно долго, до 1904 года. Издание было предназначено, скорее, не для самих женщин, а для распространения «науки о женщинах» среди мужчин. Понятие «наука о женщинах" редакторы журнала определяли следующим образом: это научные исследования о правах, статусе женщин, истории и перспективах женского вопроса. Таким образом, в Японии в связи с появлением женского журнала редакторымужчины стали заниматься женскими вопросами. В 1890 г. "Дзёгаку дзаси» подвергся серьезным изменениям: в нем стали размещать статьи по ведению домашнего хозяйства, новости о ценах на товары, методические рекомендации по уходу за больными и т. д. Для изменения содержания к редакционной и издательской работе были привлечены восемь журналистов-женщин.

В период Мэйдзи издавалось 150 женских журналов, которые разделялись на две группы: первая - это журналы националистического и консервативного толка, принципом которых являлось возвеличивание мужчин и презрение к женщинам; журналы второй группы старались привносить европеизацию в японскую культуру и общество. Но обе группы преследовали идею просвещения женщин. Затем женские журналы диверсифицировались, появились разные направ- ления, например, литературное, бытовое, идеологическое, специализированное и т. д.

С. Кояма отмечает, что в период Мэйдзи для правительства Японии вопросы строительства современного государства и подготовки кадров, которые будут поддерживать новый государственный строй, стали первостепенными задачами. В этих условиях подчеркивалась важность роли жены и матери, умеющей воспитывать детей и вести домашнее хозяйство, а также необходимость улучшения системы женского образования. Таким образом, укрепление идеи «добрая жена и умная мать» тесно связано с установлением государственной системы образования в Японии [16].

Женский журнал, редактором которого являлась именно женщина, появился в Японии в 1911 году. Он носил название «Сэйто» (Синие чулки) и выпускался под руководством писательницы Р. Хирацука ${ }^{3}$. Издание этого журнала в Японии считается эпохальным событием с точки зрения решения гендерной проблемы.

Таким образом, и в России, и в Японии женские журналы начинали издавать мужчины, считавшие необходимым просвещать женщин. Несмотря на разницу во времени появления женских журналов в двух странах (около 100 лет), и императрица Екатерина II, и японское правительство Мэйдзи возлагали надежды на новую роль женщины в обществе. Инструментом реализации этой новой женской роли явилось женское образование и издание женских журналов. В определенной мере эти издания выполняли функцию пособия для воспитания идеальных женщин на основе государственной концепции «женщина добрая жена и умная мать», в частности в Японии. Чтение и образование для женщин были необходимым средством приобретения нового мировоззрения, для того чтобы играть более заметную роль в обществе. Хотя первоначально женский журнал был предназначен для просвещения женщин с точки зрения государства, в конечном итоге женщины сами задумались о собственной судьбе и важности своей позиции в обществе.

\section{Примечания}

1 Перевод источников на русский язык выполнен автором статьи.

2 «Канадзоси» - прозаические книжки, написанные слоговой азбукой Кана. Появились в Японии в начале XVII века.

3 Хирацука Райтё - настоящее имя Окумура Хару (1886-1971), основательница движения за освобождение женщин, предоставление им избирательного права, писательница и журналист.

\section{Список источников}

1. Лотлан Ю.М. Беседы о русской культуре. Быт и традиции русского дворянства (XVIII - начала XIX века). Санкт-Петербург, 2011. С. 46. 
2. Миронов Б.Н. Социальная история России периода империи (XVIII-XX вв.) : Генезис личности, демократической семьи, гражданского общества и правового государства. Санкт-Петербург, 2000. T. 2. C. 386.

3. Самарин А.Ю. Читатель в России во второй половине XVIII века (по спискам подписчиков). Москва : Моск. гос. ун-т печати, 2000. С. 147-157.

4. Алино Ё. Пересмотр истории Японии. Токио, 2005. С. 36 - 37. (Яп. яз.).

5. Сайто Я. Исторический процесс грамотности японский опыт // Сборник статей по международному сотрудничеству Университета Хиросимы. 2012. Т. 15, № 1. С. 51-62. (Яп. яз.).

6. Майков П.М. Иван Иванович Бецкой. Опыт его биографии. Санкт-Петербург, 1904. 278 с.

7. В Петербурге учреждено «Воспитательное общество благородных девиц» (Смольный институт) [Электронный ресурс] // Президентская библиотека им. Б.Н. Ельцина. URL: http://www.prlib.ru/ History/Pages/Item.aspx?itemid=1144 (дата обращения: 01.03.2016).

8. Очерки русской культуры XVIII века. Москва, 1987. Ч. 2. С. 286.
9. 120-летняя история образования в Японии. Токио : Министерство образования Японии, 1992. С. 1737. (Яп. яз.).

10. Рассвет женских журналов. Токио : Общество изучения истории женской культуры, 1989. С. 4-7. (Яп. яз.).

11. Пушкарева Н.Л. Семейный быт Древней Руси: отношение детей и родителей // Традиции семьи. Свердловск, 1988. С. 248-263.

12. Пушкарева Н.Л. Частная жизнь русской женщины: невеста, жена, любовница. Москва, 1997. С. 75-134.

13. Модное ежемесячное издание, или Библиотека для дамского туалета [Электронный ресурс] // Музей российской печати. URL: http://mediamuseum. guru.ru/magazines/modnoe_ezhemesechnoe_izdanie (дата обращения: 01.03.2016).

14. Сокольская Л.В. Первые женские журналы для российских читательниц / / Библиосфера. 2006. № 2. C. 22.

15. Садахира M. О «Журнале науки о женщинах» // Сборник статей факультета социологии Университета Кансэй Гакуин. 1967. № 15. С. 97-102. (Яп. яз.).

16. Кояма C. Правила доброй жены и умной матери. Токио : Кэйсо, 1991. С. 234. (Яп. яз.).

\title{
The Emergence and Development of Women's Magazines in Russia and Japan (second half of 18th - 19th century)
}

\author{
Misa Nakagami, \\ Tokyo University of Foreign Studies, 3-11-1, Asahi-cho, Fuchu-shi, Tokyo, 183-8534, Japan \\ E-mail: nakagami@msh.biglobe.ne.jp
}

\begin{abstract}
The history of development of women's magazines is closely connected with the change of women's status in the society. In Russia in the 18th century the reforms of social system under Peter the Great and Catherine the Great influenced the development of education and increase of literacy rate. As a result, noblewomen joined the reading as an intellectual activity. In 1779 N.I. Novikov published the first women's magazine that marked the start of publication of books and magazines for women.

In Japan, the first women's magazine was published by hands of men in 1884 to enlighten women during the Meiji Era (1868-1912), when Japan underwent metamorphosis from the feudal society to a modern monarchy and introduced the new national system of governance, including education. The emergence of women's magazines in Japan is also related to the increase of female readers and development of system of girl's education as an instrument of state policy.

There was difference in how the concept of "woman - dutiful wife and devoted mother" was introduced in Russian and Japanese societies, but it was adopted in both countries as dominant ideology for women's education. It is concluded that women's magazines from the government point of view, based on the concept "woman - dutiful wife and devoted mother", were used to a certain extent as study guide for character education of perfect women.
\end{abstract}

Key words: Women's Magazine, Literacy, Reading, Women Readers, Women's Education, National Concept "woman - dutiful wife and devoted mother". 
Citation: Nakagami M. The Emergence and Development of Women's Magazines in Russia and Japan (second half of 18th -19 th century), Bibliotekovedenie [Library and Information Science], 2016, vol. 65, no. 3 , pp. $323-328$.

\section{References}

1. Lotman J.M. Besedy o russkoi kul'ture. Byt i traditsii russkogo dvoryanstva (XVIII - nachala XIX veka) [Talks about Russian Culture: Life and Traditions of the Russian Nobility in the 18th - the beginning of the 19th Centuries]. St. Petersburg, 2011, p. 46.

2. Mironov B.N. Sotsial'naya istoriya Rossii perioda imperii (XVIII-XX vv.: Genezis lichnosti, demokraticheskoi sem'i, grazhdanskogo obshchestva i pravovogo gosudarstva) [Russian Social History of the Empire Period (XVIII-XX centuries: The Genesis of the Personality, Democratic Family, Civil Society and Legal State)]. St. Petersburg, 2000, vol. 2, p. 386.

3. Samarin A.Yu. Chitatel'v Rossii vo vtoroi polovine XVIII veka (po spiskam podpischikov) [Readers in Russia in the Second Half of the XVIII Century (According Lists of Subscribers)]. Moscow, Mosk. gos. un-t pechati Publ., 2000, pp. 147-157.

4. Amino E. The Revision of the Japan History. Tokyo, 2005, pp. 36-37 (in Jap.).

5. Historical Process of the Literacy - Japanese Case, Collection of Articles on International Cooperation of Hiroshima University, 2012, vol. 15, no. 1, pp. 51-62 (in Jap.).

6. Maikov P.M. Ivan Ivanovich Betskoi. Opyt ego biografii [Ivan Ivanovich Betsky. The Attempt of His Biography]. St. Petersburg, 1904, 278 p.

7. V Peterburge uchrezhdeno "Vospitatel'noe obshchestvo blagorodnykh devits" (Smol'nyi institut) ["Society for Education of Noble Maidens” (Smolny Institute) established in Petersburg], Prezidentskaya biblioteka im. B.N. El'tsina [Presidential Library Named After Boris Yeltsin]. Available at: http://www.prlib.ru/ History/Pages/Item.aspx?itemid=1144 (accessed 29.03.2016).
8. Ocherki russkoi kul'tury XVIII veka [The Essays of Russian Culture of XVIII century]. Moscow, 1987, part 2, p. 286.

9. 120 Years of Japanise History Education. Tokyo, Ministry of Education of Japan Publ., 1992, pp. 17-37 (in Jap.).

10. The Rise of Women's Journals. Tokyo, Obshchestvo izucheniya istorii zhenskoi kul'tury Publ., 1989, pp. 4-7 (in Jap.).

11. Pushkareva N.L. Semeinyi byt Drevnei Rusi: otnoshenie detei i roditelei [Family Household of Ancient Russia: The Relationship of Children and Parents], Traditsii sem'i [Family Traditions]. Sverdlovsk, 1988, pp. 248-263.

12. Pushkareva N.L. Chastnaya zhizn' russkoi zhenshchiny: nevesta, zhena, lyubounitsa [Private Life of Russian Woman: Bride, Wife, Mistress]. Moscow, 1997, pp. 75-134.

13. Modnoe ezhemesyachnoe izdanie ili Biblioteka dlya damskogo tualeta [Fashion Monthly Edition or the Library for Ladies Toilette], Muzei rossiiskoi pechati [Museum of the Russian Press]. Available at: http://mediamuseum.guru.ru/magazines/modnoe_ ezhemesechnoe_izdanie (accessed 29.03.2016).

14. Sokol'skaya L.V. Pervye zhenskie zhurnaly dlya rossiiskikh chitatel'nits [First Women's Magazines for Russian Readers], Bibliosfera [Bibliosphere], 2006, no. 2 , p. 22.

15. Sadakhira M. On the Journal "Science of Women", Articles' Collection of the Sociology Faculty, Kwansei Gakuin University, 1967, no. 15, pp. 97-102 (in Jap.).

16. Koyama S. Pravila dobroi zheny i umnoi materi [The Rules of Good Wife and Clever Mother]. Tokyo, Keiso Publ., 1991, p. 234 (in Jap.). 